\title{
Pemrograman Ladder PLC Pada Otomasi Proses Produksi Bioetanol Berbasis Jala Petri Sinyal Terinterpretasi (JPST)
}

\author{
Endra Joelianto $^{1 *}$, Alex Dananjaya ${ }^{2}$ \\ ${ }^{1}$ Kelompok Keahlian Instrumentasi dan Kontrol, Fakultas Teknologi Industri, Institut Teknologi Bandung, \\ ${ }^{2}$ Alumni Program Studi Teknik Fisika, Fakultas Teknologi Industri, Institut Teknologi Bandung, \\ Jl. Ganesha 10, Bandung, Indonesia 40132
}

\begin{abstract}
Abstrak
Jala Petri Sinyal Terinterpretasi (JPST) dikenal sebagai salah satu metode formal yang digunakan untuk merancang dan mengevaluasi perilaku sistem otomasi yang dimodelkan sebagai sistem kejadian diskrit. Hubungan antara algoritma kontrol biner yang dibangun dengan proses sekuensial yang ditinjau dapat diperlihatkan dengan menggunakan JPST. Aplikasi diagram JPST pada perangkat keras umum seperti PLC memerlukan suatu cara untuk mengkodekan representasi algoritma kontrol dalam bentuk grafik menjadi program logika ladder. Makalah ini memperlihatkan proses pengubahan algoritma sistem otomasi proses produksi bioetanol yang dibangun dengan menggunakan metode JPST menjadi program logika ladder. Kinerja program ladder yang dihasilkan untuk sistem otomasi proses produksi bioetanol menggunakan PLC mengikuti kinerja dari diagram JPST yang dibuat.
\end{abstract}

Kata kunci: jala petri; jala petri sinyal terinterpretasi; produksi bioetanol; program ladder; kontrol biner; otomasi

\begin{abstract}
[Title: Ladder Programming of PLC for Automation of Bioethanol Production Process Based on Signal Interpreted Petri Net (SIPN)] Signal Interpreted Petri Net (SIPN) is known as one of the formal methods used to design and evaluate the behavior of automation systems modeled as discrete event systems. The relationship between binary control algorithms that are built with sequential processes can be shown using SIPN. The application of SIPN diagrams to common hardware such as PLCs requires a way to encode the control algorithm's representation in graphical form into a ladder logic program. This paper shows the process of changing the algorithm for automation of the bioethanol production process built using the SIPN method into a logic ladder program. The performance of the ladder program produced for the bioethanol production process automation system using SIPN follows the performance of the SIPN diagram made.
\end{abstract}

Keywords: petri net; signal interpreted petri net; bioethanol production; ladder program; binary control; automation

\section{Pendahuluan}

Saat ini, efisiensi, hemat biaya (cost effective), fleksibilitas yang menjadi tuntutan dalam persaingan industri proses atau manufaktur telah meningkatkan permintaan yang luar biasa terhadap kinerja sistem kontrol industri. Kriteria sistem kontrol industri yang diharapkan adalah kriteria kinerja kecepatan (speed),

\footnotetext{
*) Penulis Korespondensi.

E-mail: ejoel@tf.itb.ac.id
}

doi: $10.14710 /$ teknik.v41n2.24638 kehandalan (reliability) dan ketepatan (correctness). Sistem kontrol merupakan sistem yang mempunyai kemampuan untuk memulai, mengatur dan menghentikan suatu proses sebagai respon terhadap variabel-variabel yang diukur atau dimonitor dalam proses tersebut, dengan tujuan mendapatkan keluaran yang memenuhi spesifikasi perancangan yang diinginkan oleh pengguna.

Perancangan kontrol biner termasuk perancangan kontrol secara perangkat lunak dengan merealisasikan algoritma kontrol logika dengan transparansi dan 


\section{TEKNIK, 41 (2), 2020, 153}

keabsahan sebaik mungkin. Kontrol biner ditinjau sebagai sistem kejadian diskrit (discrete event system), yaitu sistem yang perubahan keadaannya terjadi dalam satu satuan waktu diskrit sebagai tanggapan terhadap keberadaan kejadian (event) tertentu. Dengan demikian, pengontrolan sistem dilakukan dengan masukan dan keluaran yang terbatas jumlahnya serta hanya memiliki dua keadaan, yaitu "on" dan "off'. Gambar 1 memperlihatkan skema proses perancangan sistem kontrol logika menggunakan kontrol biner. Bagian kanan skema memperlihatkan aliran pembuatan algoritma otomasi dengan menggunakan metode dan spesifikasi formal. Cara formal mampu memberikan ukuran kinerja algoritma otomasi yang dibangun dibandingkan dengan cara implementasi langsung yang cenderung intuitif dan tergantung mutlak pada kemampuan individu pemrogramnya tanpa ukuran kinerja yang dapat menunjukkan kehandalan dan ketepatan sistem kontrol yang dihasilkan.

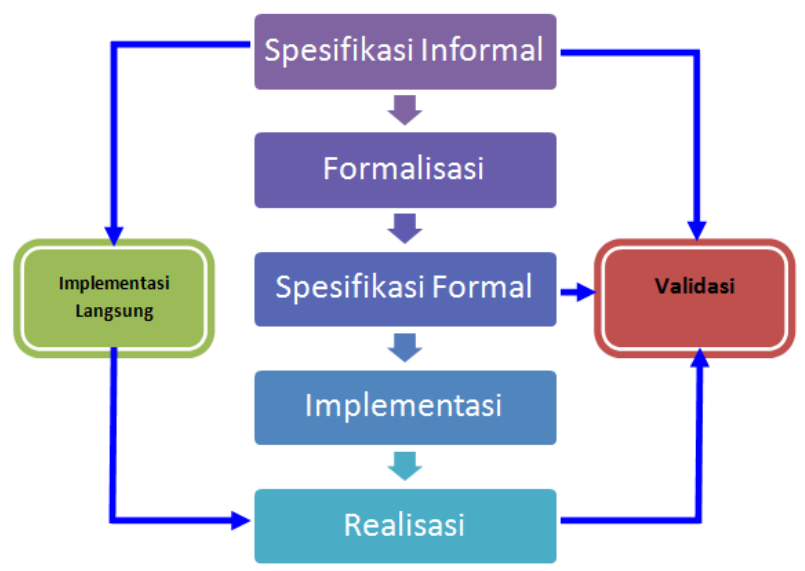

Gambar 1. Proses perancangan sistem kontrol logika

Kontrol logika terprogram atau lebih dikenal sebagai programmable logic controller (PLC) merupakan sistem elektronik yang beroperasi secara dijital dan dirancang untuk digunakan pada suatu lingkungan industri yang menggunakan suatu memori yang dapat diprogram. Bentuk memori tersebut merupakan penyimpanan internal instruksi-instruksi yang dapat menerapkan fungsi-fungsi tertentu seperti fungsi logika, pewaktuan, perhitungan untuk mengontrol melalui modul masukan atau keluaran analog maupun dijital beberapa jenis proses dan mesin. PLC sebagai pengontrol muncul pada akhir tahun enampuluhan pada era disebut otomasi yang dikenal sekarang sebagai Industri 3.0. Sebagai hasil dari suatu usaha untuk memperoleh sistem logika yang memiliki sifat-sifat: mudah diprogram dan diprogram ulang di lokasi dan terbentuk dari bahan solid-state sehingga mempunyai kehandalan yang tinggi. Walaupun tujuan semula PLC adalah untuk menggantikan relai dan stepper elektromagnetik, pada akhirnya PLC telah berkembang menjadi peralatan yang mirip komputer yang dapat melakukan berbagai macam fungsi lain, selain logika relai (relay logic).

Pada saat ini, PLC yang memulai era Industri 3.0 adalah komponen utama pada sistem otomasi dalam berbagai aplikasi dan proses industri (Kumar $d k k$., 2016a; Bargal dkk., 2016; Baladhandabany $d k k ., 2015$; Patil $d k k ., 2016$; Zhu \& Qiu, 2017; Kumar $d k k ., 2016$ b; Ayten $\&$ Kurnaz, 2019). PLC merupakan keharusan yang tidak dapat dielakkan dan ditunda lagi. Bahkan, di era Industri 4.0, PLC masih merupakan komponen pengontrol utama yang terintegrasi dengan Internet of Things (IoT) dan sistem fisik siber (Cyber Physical System, CPS) (Petrusich \& Schwarz, 2017; Wanyama, 2018; Langmann \& Rojas-Peña, 2016; Zhou dkk., 2015; Papcun dkk., 2018; Baygin $d k k$., 2016; Wittenberg, 2016).

Metode formal (formal method) untuk memverifikasi program PLC akhir-akhir ini juga mendapatkan perhatian yang besar. Beberapa metode formal telah dikembangkan Darvas $d k k$. (2016a), Darvas $d k k$. (2016b), Vieira $d k k$. (2016), dan Julius $d k k$. (2017). Keunggulan pembuatan program PLC dengan metode formal adalah kebuntuan (dead lock) dan kehandalan dapat dianalisis sebelum program akan diaplikasikan pada saat pengoperasian PLC.

Proses fermentasi anaerob oleh mikroba Saccharomyces cerevisiae menghasilkan etanol $\left(\mathrm{CH}_{3-}^{-}\right.$ $\left.\mathrm{CH}_{2}-\mathrm{OH}\right)$. Ketika Saccharomyces cerevisiaem melakukan metabolisme terhadap karbohidrat dalam kondisi anaerob, maka dihasilkan etanol, karbon dioksida dan energi. Reaksi yang terjadi termasuk reaksi eksotermal, dan menghasilkan kalor reaksi sebesar 210 $\mathrm{kJ} / \mathrm{mol}$ glukosa. Sehingga harus diusahakan agar reaksi dapat berlangsung secara isotermal. Secara sederhana sesuai (Shuler $d k k ., 2017$ ), reaksi fermentasi etanol terlihat pada Persamaan 1.

$$
\mathrm{C}_{6} \mathrm{H}_{12} \mathrm{O}_{6} \longrightarrow 2 \mathrm{C}_{2} \mathrm{H}_{5} \mathrm{OH}+2 \mathrm{CO}_{2}+2 \mathrm{ATP}+210 \mathrm{~kJ}
$$

Reaksi fermentasi Persamaan 1 juga menghasilkan produk tambahan berupa 2 ATP yang menjadi sumber energi bagi metabolisme sel.

Proses produksi bioetanol terdiri atas tahapantahapan, setiap tahapan proses perlu dikontrol dengan benar dan tepat agar didapatkan perolehan produk bioetanol dengan kualitas dan kuantitas yang diharapkan. Proses enzimatik pati dari bahan baku singkong menjadi alkohol melalui proses pemasakan secara umum diperlihatkan dalam Gambar 2. 


\section{TEKNIK, 41 (2), 2020, 154}

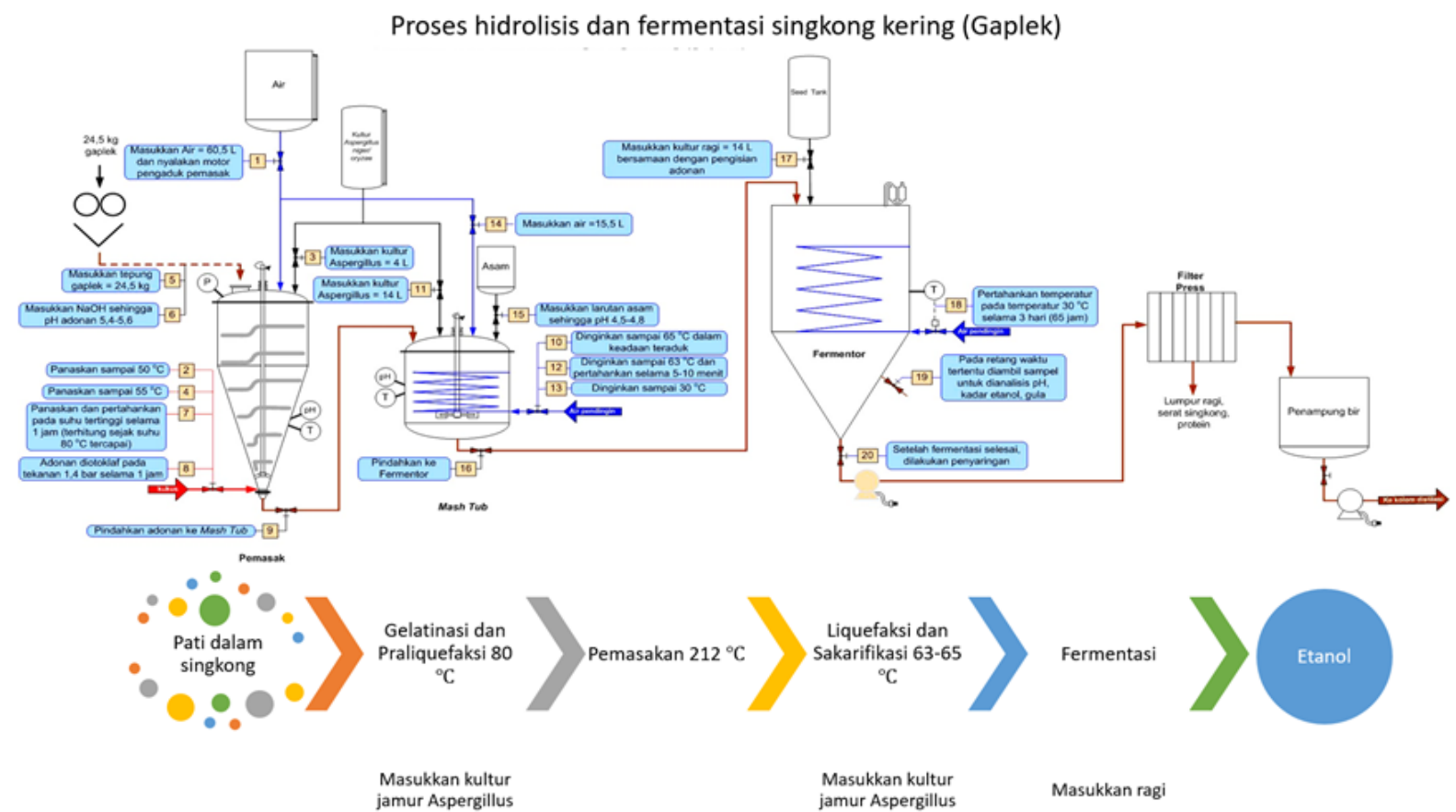

Gambar 2. Diagram proses produksi bioetanol dari singkong kering (gaplek) (Joelianto \& Dananjaya, 2008)

Pada proses produksi bioetanol, setiap keluaran dari tahapan harus baik agar tahapan secara keseluruhan optimal. Hal ini dapat dicapai jika beberapa parameter dapat dikontrol nilainya atau kebutuhannya. Sistem instrumentasi dan kontrol beserta dengan mekanisme otomatik menjadi bagian yang penting untuk mengontrol variabel proses dan menjalankan kontrol pada setiap tahap pembuatan agar bioetanol yang dihasilkan maksimum dan berkualitas baik. Sistem otomasi dibangun berdasarkan kondisi-kondisi pemrosesan yang diperlihatkan dalam Gambar 2.

Sistem otomasi merupakan bagian yang vital untuk menghasilkan suatu proses produksi yang optimal, efisien dan handal karena kemampuannya untuk melakukan pengukuran dengan waktu cacah yang lebih cepat, hasil yang lebih akurat dan konsisten dalam melakukan pengontrolan. Tetapi, sistem otomasi sangat tergantung pada perangkat keras dan lunak yang digunakan. Perangkat keras yang sering digunakan pada saat ini adalah PLC dengan perangkat lunak yang secara umum masih diprogram dengan program ladder. Persoalan utama yang sering terjadi adalah pemrogram PLC melakukan pemrograman secara coba-coba dan dengan alur kerja berdasarkan pengalaman. Sehingga suatu metode formal yang mampu menganalisis dan mengevaluasi program yang dihasilkan serta dapat dilacak kembali hasilnya akan dapat menjamin ukuran kinerja yang dihasilkan.

Banyak metode formal yang mulai dikembangkan untuk menganalisis dan mengevaluasi program kontrol biner. Jala Petri (Petri net) merupakan metode formal pertama yang diperkenalkan oleh C.A. Petri dalam disertasi doktornya di akhir tahun 1960-an. Selanjutnya, Jala Petri mulai banyak mengalami perbaikan dan penambahan menjadi berbagai macam variasi Jala Petri, salah satu variasi adalah Jala Petri Sinyal Terinterpretasi (JPST) atau Signal Interpreted Petri Nets (SIPN) (Frey, 2000; Frey \& Litz, 2000). JPST adalah Jala Petri yang bisa menggambarkan hubungan antara algoritma yang disusun dengan lingkungannya. Keterkaitan antara algoritma dengan lingkungannya ditunjukkan melalui sinyal masukan dan sinyal keluaran.

JPST telah diaplikasikan untuk perancangan beberapa sistem otomasi seperti boiler (Joelianto \& Loeis, 2006) dan sistem pengaman keselamatan (safety shutdown system) (Leonardo dkk., 2015). Keperluan penerapan sistem otomasi yang terstruktur dan baik secara khusus pada proses curah (batch process) juga telah menjadi persyaratan industri seperti direkomendasikan oleh masyarakat Instrumentation, System and Automation (ISA) yang mengeluarkan standar S88 (ISA, 2002). Penggunaan metode formal seperti JPST akan mengurangi kegagalan aplikasi sistem otomasi menggunakan PLC yang diprogram berbasis program ladder.

JPST telah digunakan juga untuk merancang sistem otomasi pada proses pembuatan bioetanol (Joelianto \& Dananjaya, 2008) supaya produksi ekonomis dan menghasilkan kualitas produk yang tinggi. JPST tersebut dianalisis dengan menggunakan metode analisis invarian (Wang, 1998) dan grafik ketercapaian (Frey \& Litz, 2000) untuk mendapatkan 


\section{TEKNIK, 41 (2), 2020, 155}

kinerja algoritma yang baik dan mempunyai metrik transparansi tinggi. Langkah-langkah tersebut dilakukan sebagai cara untuk menghasilkan sistem otomasi yang berkinerja tinggi. Makalah ini membahas pengkodean sistem otomasi proses bioetanol yang telah dirancang menggunakan JPST (Joelianto \& Dananjaya, 2008) menjadi bahasa pemrograman PLC dalam bentuk program ladder.

\section{Bahan dan Metode}

2.1 Perancangan Otomasi Proses Produksi Bioetanol Proses pembuatan bioetanol dari bahan baku singkong secara ringkas yang akan dirancang sistem otomasinya dapat dilihat pada referensi (Joelianto \& Dananjaya, 2008). Dari proses tersebut, daftar sinyal masukan dan keluaran yang berhubungan dengan sensor, aktuator pada sistem otomasi dapat disusun seperti yang diperlihatkan pada Tabel 1 di bawah ini. Dari data-data masukan dan keluaran, aliran proses dan ketentuanketentuan pada variabel-variabel proses pembuatan bioetanol yang perlu dikontrol, diagram JPST untuk otomasi proses bioetanol yang memenuhi kriteria keterbatasan, keselamatan dan daya hidup telah disusun pada (Joelianto \& Dananjaya, 2008).

Berdasarkan (Frey \& Minas, 2001), ketepatan formal (formal correctness) memperlihatkan ukuran prasyarat untuk algoritma yang berfungsi, sedangkan transparansi (transparency) adalah ukuran kualitas perancangan algoritma. Algoritma dikatakan transparan jika apa yang dilakukan pengontrol pada saat ini dan apa yang akan dilakukannya di langkah selanjutnya dapat dengan mudah dan jelas untuk dilihat. Sejumlah kriteria transparansi telah dijelaskan secara lengkap pada (Frey \& Litz, 2000). Kriteria transparansi mencakup berbagai aspek seperti jumlah komentar (number of comments), arah (directionality), dan perilaku masukan/keluaran (Input/Output-behaviour). Ketiga faktor selanjutnya digabungkan dalam jumlah terbobot menjadi suatu ukuran transparansi yang dapat dihitung secara otomatis. Metrik tranparansi bernilai 1 berarti program sangat transparan (fully transparent).

Hasil kalkulasi diagram JPST (Joelianto \& Dananjaya, 2008) yang dibangun memiliki metrik transparansi 0,98 yang sangat dekat dengan 1. Hasil ini memperlihatkan bahwa JPST lebih transparan atau lebih mudah untuk dipahami. Nilai metrik transparasi ini juga berarti bahwa diagram JPST yang disusun terdokumentasi dengan baik sehingga dapat diterapkan menjadi program ladder di PLC.
Makna notasi pada Gambar 3 adalah $P$ merupakan sejumlah tempat (Places); $\mathrm{T}$ adalah sejumlah transisi (Transitions); $\mathrm{O}$ adalah sejumlah sinyal keluaran; $\varphi$ adalah pemetaan yang menghubungkan setiap transisi Ti $\varepsilon$ T dengan kondisi penembakan, $\varphi(\mathrm{Ti})$ $=$ fungsi Boolean dalam I; $\omega$ adalah pemetaan yang menghubungkan setiap tempat $\mathrm{Pi} \varepsilon \mathrm{P}$ dengan keluaran $\omega(\mathrm{Pi}) \varepsilon(0,1,-)|\mathrm{O}|,(-)$ berarti sinyal tidak dipedulikan.

Tabel 1. Sinyal Masukan dan Sinyal Keluaran

\begin{tabular}{|c|c|}
\hline MASUKAN (kondisi aktif) & KELUARAN (kondisi aktif) \\
\hline $\mathrm{i}_{1}$ : tombol "mulai" ditekan & $\mathrm{o}_{1}$ : katup air ke tangki pemasak membuka \\
\hline $\mathrm{i}_{2}$ : air sudah $60,5 \mathrm{~L}$ & $\mathrm{o}_{2}$ : katup air mash tube membuka \\
\hline $\mathrm{i}_{3}$ : tangki pemasak sudah $50^{\circ} \mathrm{C}$ & $\begin{array}{l}\mathrm{o}_{3}: \text { katup uap pemanas ke tangki pemasak } \\
\text { membuka }\end{array}$ \\
\hline $\mathrm{i}_{4}$ : kultur Aspergillus sudah $4 \mathrm{~L}$ & $\mathrm{o}_{4}:$ katup air pendingin ke mash tube membuka \\
\hline $\mathrm{i}_{5}$ : tangki pemasak sudah $55^{\circ} \mathrm{C}$ & $\mathrm{o}_{5}:$ katup air pemanas ke fermentor membuka \\
\hline$i_{6}$ : tepung gaplek sudah $24,5 \mathrm{~kg}$ & $\begin{array}{l}\mathrm{o}_{6}: \text { katup kultur Aspergillus ke tangki pemasak } \\
\text { membuka }\end{array}$ \\
\hline $\begin{array}{l}\mathrm{i}_{7} \text { : asam tangki pemasak sudah } 20 \\
\mathrm{~mL}\end{array}$ & $\begin{array}{l}\mathrm{o}_{7}: \text { katup kultur Aspergillus ke mash tube } \\
\text { membuka }\end{array}$ \\
\hline $\mathrm{i}_{8}: \mathrm{pH}>5,4$ & $\mathrm{o}_{8}$ : katup kultur ragi ke fermentor membuka \\
\hline $\mathrm{i}_{9}: \mathrm{pH}<5,6$ & $\mathrm{o}_{9}:$ katup asam ke tangki pemasak membuka \\
\hline $\begin{array}{l}\mathrm{i}_{10} \text { : basa tangki pemasak sudah } 20 \\
\mathrm{~mL}\end{array}$ & $\mathrm{o}_{10}$ : katup basa ke tangki pemasak membuka \\
\hline $\mathrm{i}_{11}$ : tangki pemasak $80^{\circ} \mathrm{C}$ & $\mathrm{o}_{11}$ : katup asam ke mash tube membuka \\
\hline $\mathrm{i}_{12}$ : tekanan $>1,39$ bar & $\mathrm{o}_{12}$ : katup basa ke mash tube membuka \\
\hline $\mathrm{i}_{13}$ : tekanan $<1,41$ bar & $\mathrm{o}_{13}$ : pengaduk tangki pemasak aktif \\
\hline $\mathrm{i}_{14}$ : otoklaf sudah $1 \mathrm{jam}$ & $\mathrm{o}_{14}:$ pengaduk mash tube aktif \\
\hline$i_{15}$ : tangki pemasak kosong & $\begin{array}{l}\mathrm{o}_{15}: \text { katup tangki pemasak ke mash tube } \\
\text { membuka }\end{array}$ \\
\hline$i_{16}:$ suhu mash tube $65^{\circ} \mathrm{C}$ & $\mathrm{o}_{16}:$ katup mash tube ke fermentor membuka \\
\hline $\mathrm{i}_{17}:$ kultur Aspergillus $14 \mathrm{~L}$ & $\mathrm{o}_{17}:$ katup fermentor ke penyaring membuka \\
\hline $\mathrm{i}_{18}:$ suhu $>62^{\circ} \mathrm{C}$ & $\mathrm{o}_{18}:$ timer tangki pemasak aktif \\
\hline $\mathrm{i}_{19}:$ suhu $<64^{\circ} \mathrm{C}$ & $\mathrm{o}_{19}:$ timer mash tube aktif \\
\hline $\mathrm{i}_{20}$ : sudah 10 menit & $\mathrm{o}_{20}:$ timer fermentor aktif \\
\hline$i_{21}:$ suhu $30^{\circ} \mathrm{C}$ & $\begin{array}{l}\mathrm{o}_{21} \text { : lampu pertanda bahwa pemasukan tepung } \\
\text { gaplek sudah bisa dilakukan menyala }\end{array}$ \\
\hline \multicolumn{2}{|l|}{$\mathrm{i}_{22}: \operatorname{air} 15,5 \mathrm{~L}$} \\
\hline \multicolumn{2}{|l|}{$\mathrm{i}_{23}:$ asam mash tube sudah $20 \mathrm{~mL}$} \\
\hline \multicolumn{2}{|l|}{$\mathrm{i}_{24}: \mathrm{pH}>4,5$} \\
\hline \multicolumn{2}{|l|}{$\mathrm{i}_{25}: \mathrm{pH}>4,8$} \\
\hline \multicolumn{2}{|l|}{$\mathrm{i}_{26}:$ basa mash tube sudah $20 \mathrm{~mL}$} \\
\hline \multicolumn{2}{|l|}{$\mathrm{i}_{27}: \operatorname{ragi} 14 \mathrm{~L}$} \\
\hline \multicolumn{2}{|l|}{$i_{28}:$ suhu $>31^{\circ} \mathrm{C}$} \\
\hline \multicolumn{2}{|l|}{$\mathrm{i}_{29}:$ suhu $<32^{\circ} \mathrm{C}$} \\
\hline \multicolumn{2}{|l|}{$\mathrm{i}_{30}:$ sudah $65 \mathrm{jam}$} \\
\hline $\mathrm{i}_{31}:$ fermentor kosong & \\
\hline
\end{tabular}


TEKNIK, 41 (2), 2020, 156
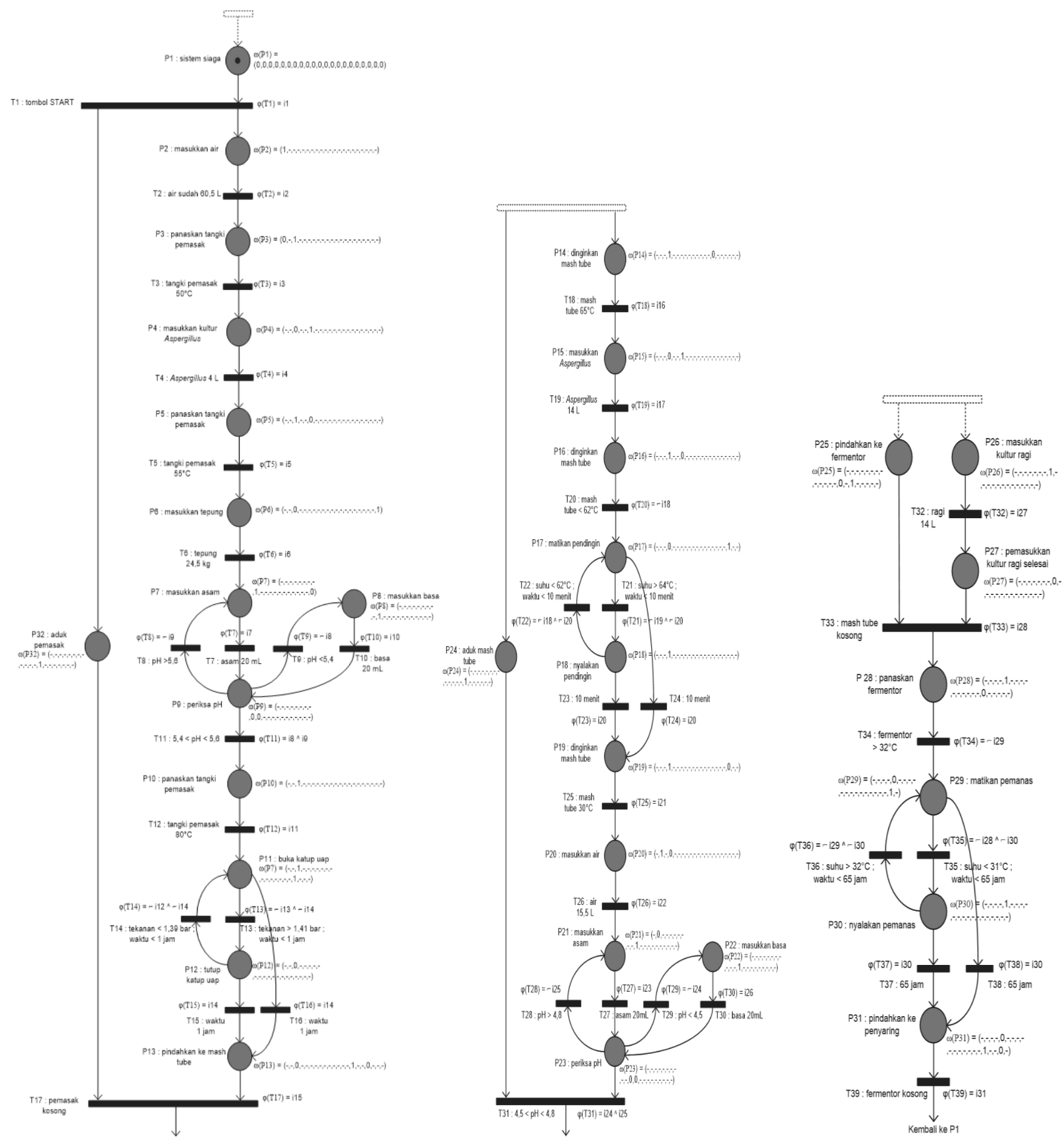

Gambar 3. Diagram JPST sistem otomasi proses fermentasi bioetanol (Joelianto \& Dananjaya, 2008) 


\section{TEKNIK, 41 (2), 2020, 157}

\subsection{Representasi JPST dalam Program Ladder}

Setelah mengalami validasi dengan menggunakan analisis sifat-sifat yang dimiliki JPST untuk menjamin keselamatan rancangan sistem kontrol tersebut, pengkodean algoritma JPST pada PLC siap dilakukan dengan membuat program ladder dan daftar instruksi berdasarkan JPST yang dimaksud. Place (tempat) yang tertandai akan memberikan nilai $\mathrm{Pi}=$ benar dan Place yang tidak tertandai akan memberikan nilai $\mathrm{Pi}=$ salah. Penyusunan sebuah Transisi terjadi dengan pemeriksaan apakah Transisi tersebut siap dan apakah kondisi pemicuan dipenuhi.

Tata cara penyusunan daftar instruksi dan program ladder berdasarkan JPST yang bersangkutan (Frey, 2000) adalah:

1. Pengkodean Transisi

\begin{tabular}{|c|c|c|}
\hline Ti: LD & PP1 & (* Ti: jika place awal PP1 tertandai $*)$ \\
\hline AND & PP2 & $(*$ jika place awal PP2 tertandai $*)$ \\
\hline ANDN & Pp1 & $\begin{array}{l}(* \text { dan place tujuan Pp1 tidak } \\
\text { tertandai } *)\end{array}$ \\
\hline ANDN & $\mathrm{Pp} 2$ & $\begin{array}{l}(* \text { dan place tujuan } \mathrm{Pp} 2 \text { tidak } \\
\text { tertandai } *)\end{array}$ \\
\hline AND & $f(E)$ & (* dan kondisi pemicuan terpenuhi) \\
\hline
\end{tabular}

2. Pengkodean Place

$$
\begin{aligned}
& \text { Pi: } \quad \text { LD } \quad \text { Pi } \quad \text { (* jika place Pi ditandai *) } \\
& \text { S Oi } \quad(* \text { set } \mathrm{Oi} *) \\
& \text { R } \quad \text { Oj } \quad(* \text { dan reset } \mathrm{Oj} *) \\
& \text { LD } \quad \text { Pj } \quad \text { (*... jika place Pj ditandai }
\end{aligned}
$$

Diketahui terdapat suatu JPST yang memenuhi kriteria keselamatan (safe) dan memiliki daya hidup (live):

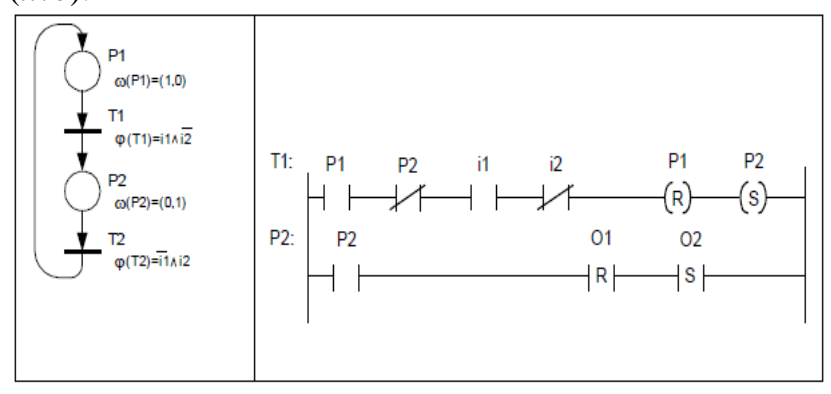

Berikut merupakan cara lain merepresentasikan pengkodean PLC bagi contoh kasus di atas beserta komentar langkah-langkah yang terjadi.

$$
\begin{aligned}
& \text { T1: LD } \quad \text { P1 } \quad \text { (* T1: jika pre-place P1 ditandai *) } \\
& \text { ANDN P2 (* dan post-place P2 tidak tertandai *) } \\
& \text { AND i1 (* dan kondisi pemicuan dipenuhi } * \text { ) } \\
& \text { ANDN i2 } \\
& \text { P2: } \mathrm{R} \quad \mathrm{P} 1 \quad \text { (* kemudian hilangkan penandaan } \\
& \text { pre-place } \mathrm{P} 1 * \text { ) } \\
& \mathrm{S} \quad \mathrm{P} 2 \quad(* \text { dan tandai post-place } \mathrm{P} 2 *)
\end{aligned}
$$

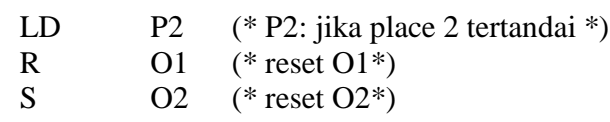

\subsection{Penerapan pada PLC}

Dari algoritma yang telah disusun dalam bentuk JPST akan dibuat diagram logika ladder (Ladder Logic Diagram) untuk diterapkan menjadi program ladder (ladder program) pada PLC. Pembuatan program ladder dari JPST mengikuti aturan: (1) Tempat (Place), dimana setiap tempat diubah menjadi peubah Boolean yang akan bernilai logika 1 apabila tempat bertanda dan bernilai logika 0 apabila tempat tidak bertanda; (2) Transisi (Transition), dimana pengubahan transisi ke program ladder harus dapat memeriksa siap atau tidaknya suatu transisi terpicu dan kondisi pemicuannya. Pemicuan ini akan mengakibatkan tempat asal bernilai 0 dan tempat tujuan bernilai 1 . Ini adalah mekanisme perpindahan penanda; (3) Masukan, dimana sinyal masukan dan kombinasinya akan mengaktifkan transisi sesuai dengan kondisi yang telah ditentukan; (4) Keluaran, dimana keluaran yang berhubungan dengan tempat yang sedang bernilai 1 akan segera diaktifkan atau dimatikan sesuai dengan kondisi yang telah ditentukan; (5) Penembakan (Firing); dimana proses penembakan akan terjadi jika semua tempat asal bertanda, semua tempat tujuan tidak bertanda, dan kondisi pemicuan terpenuhi.

Program ladder dibuat menggunakan perangkat lunak TwidoSoft V-3.2 yang digunakan untuk memprogram PLC Twido keluaran dari Schneider-Telemecanique. Setiap objek dalam JPST diwakili oleh sebuah alamat bit pengingat (memory bit). Daftar alamat bit pengingat dengan tempat dan transisi diberikan pada Tabel 2.

Dari pemetaan bit pengingat tersebut, program ladder dari JPST sistem otomasi proses fermentasi bioetanol pada Gambar 3 dibuat dengan menggunakan perangkat lunak TwidoSoft V-3.2 untuk menyatakan proses penembakan dan keadaan keluaran. Program ladder yang dihasilkan diperlihatkan oleh Gambar 4.

\section{Hasil dan Pembahasan}

Simulasi proses penembakan dibuat menggunakan perangkat lunak Wonderware InTouch 9.0 yang dihubungkan dengan PLC melalui perangkat lunak TOP Server yang bertindak sebagai open process control $(O P C)$ melalui komunikasi serial RS-232/485 diperlihatkan oleh Gambar 5. Program ladder Gambar 4 yang telah disimpan dalam PLC selanjutnya dilakukan pengetesan dengan cara mengirimkan data " $T$ ", "P" dan "O" pada Tabel 1 yang terdapat dalam "alamat" di PLC menjadi "tag name" setelah melewati TOP Server yang selanjutnya ditampilkan di human machine interface (HMI) dengan menggunakan Wonderware InTouch 9.0. Selanjutnya, perubahan " $T$ " dan "P" dapat disimulasikan melalui $H M I$ dan pengaruhnya akan dikirimkan ke PLC 


\section{TEKNIK, 41 (2), 2020, 158}

dengan proses terbalik (tag name menjadi alamat) dan efeknya terhadap yang lain akan tampil kembali di $H M I$.

Tampilan simulasi proses penembakan yang diujikan bisa dilihat pada HMI diperlihatkan oleh Gambar 6-9. Gambar 6 memperlihatkan tampilan kejadian diskrit yang terdapat pada tangki pemasak. Kejadian diskrit pada mash tube diperlihatkan pada Gambar 7. Gambar 8 memperlihatkan proses yang terjadi pada bagian fermentor. Sedangkan Gambar 9 memperlihatkan kondisi hidup atau mati dari keluaran proses otomasi. Pengujian simulasi memperlihatkan bahwa otomasi proses, dalam bentuk urutan terpicu "T" dan perpindahan "P" yang dilakukan oleh program ladder untuk mengubah keluaran "O" berjalan seperti yang sudah dirancang sesuai dengan kebutuhan operasi proses fermentasi bioetanol Gambar 2.

Tabel 2. Alamat bit pengingat dalam PLC TWIDO yang digunakan untuk mewakili objek dalam JPST

\begin{tabular}{|c|c|c|c|c|c|}
\hline Transisi & Alamat & Tempat & Alamat & Keluaran & Alamat \\
\hline T1 & \%M101 & P1 & $\% \mathrm{M} 1$ & O1 & \%M41 \\
\hline $\mathrm{T} 2$ & $\%$ M102 & $\mathrm{P} 2$ & $\% \mathrm{M} 2$ & $\mathrm{O} 2$ & $\%$ M42 \\
\hline $\mathrm{T} 3$ & $\%$ M103 & P3 & $\% \mathrm{M} 3$ & $\mathrm{O} 3$ & $\%$ M43 \\
\hline $\mathrm{T} 4$ & $\%$ M104 & P4 & $\% \mathrm{M} 4$ & $\mathrm{O} 4$ & $\%$ M44 \\
\hline $\mathrm{T} 5$ & $\%$ M105 & P5 & $\%$ M5 & O5 & $\%$ M45 \\
\hline T6 & $\%$ M106 & P6 & $\%$ M6 & O6 & $\%$ M46 \\
\hline $\mathrm{T} 7$ & $\%$ M107 & P7 & $\% \mathrm{M} 7$ & O7 & $\%$ M47 \\
\hline $\mathrm{T} 8$ & $\%$ M108 & P8 & $\% \mathrm{M} 8$ & $\mathrm{O} 8$ & $\%$ M48 \\
\hline T9 & $\%$ M109 & P9 & $\% \mathrm{M} 9$ & O9 & $\%$ M49 \\
\hline $\mathrm{T} 10$ & $\% \mathrm{M} 110$ & P10 & $\% \mathrm{M} 10$ & $\mathrm{O} 10$ & $\%$ M50 \\
\hline $\mathrm{T} 11$ & $\%$ M111 & P11 & $\% \mathrm{M} 11$ & O11 & $\% \mathrm{M} 51$ \\
\hline $\mathrm{T} 12$ & $\% \mathrm{M} 112$ & $\mathrm{P} 12$ & $\% \mathrm{M} 12$ & $\mathrm{O} 12$ & $\% \mathrm{M} 52$ \\
\hline $\mathrm{T} 13$ & $\%$ M113 & P13 & $\%$ M13 & $\mathrm{O} 13$ & $\%$ M53 \\
\hline $\mathrm{T} 14$ & $\%$ M114 & P14 & $\%$ M14 & O14 & $\%$ M54 \\
\hline $\mathrm{T} 15$ & $\% \mathrm{M} 115$ & P15 & $\%$ M15 & O15 & $\%$ M55 \\
\hline T16 & $\%$ M116 & P16 & $\%$ M16 & O16 & $\%$ M56 \\
\hline $\mathrm{T} 17$ & $\% \mathrm{M} 117$ & P17 & $\%$ M17 & $\mathrm{O} 17$ & $\%$ M57 \\
\hline $\mathrm{T} 18$ & $\%$ M118 & P18 & $\% \mathrm{M} 18$ & $\mathrm{O} 18$ & $\%$ M58 \\
\hline T19 & $\%$ M119 & P19 & $\%$ M19 & O19 & $\%$ M59 \\
\hline $\mathrm{T} 20$ & $\% \mathrm{M} 120$ & P20 & $\%$ M20 & $\mathrm{O} 20$ & $\%$ M60 \\
\hline $\mathrm{T} 21$ & $\% \mathrm{M} 121$ & $\mathrm{P} 21$ & $\% \mathrm{M} 21$ & $\mathrm{O} 21$ & $\% \mathrm{M} 61$ \\
\hline $\mathrm{T} 22$ & $\%$ M122 & $\mathrm{P} 22$ & $\%$ M22 & & \\
\hline $\mathrm{T} 23$ & $\%$ M123 & $\mathrm{P} 23$ & $\%$ M23 & & \\
\hline $\mathrm{T} 24$ & $\% \mathrm{M} 124$ & P24 & $\%$ M24 & & \\
\hline $\mathrm{T} 25$ & $\%$ M125 & $\mathrm{P} 25$ & $\%$ M25 & & \\
\hline $\mathrm{T} 26$ & $\% \mathrm{M} 126$ & P26 & $\%$ M26 & & \\
\hline $\mathrm{T} 27$ & $\%$ M127 & P27 & $\%$ M27 & & \\
\hline $\mathrm{T} 28$ & $\% \mathrm{M} 128$ & P28 & $\% \mathrm{M} 28$ & & \\
\hline $\mathrm{T} 29$ & $\%$ M129 & P29 & $\% \mathrm{M} 29$ & & \\
\hline $\mathrm{T} 30$ & $\% \mathrm{M} 130$ & P30 & $\%$ M30 & & \\
\hline $\mathrm{T} 31$ & $\% \mathrm{M} 131$ & P31 & $\%$ M31 & & \\
\hline $\mathrm{T} 32$ & $\%$ M132 & P32 & $\%$ M32 & & \\
\hline T33 & $\% \mathrm{M} 133$ & & & & \\
\hline T34 & $\%$ M134 & & & & \\
\hline T35 & $\%$ M135 & & & & \\
\hline T36 & $\%$ M136 & & & & \\
\hline T37 & $\%$ M137 & & & & \\
\hline T38 & $\%$ M138 & & & & \\
\hline T39 & $\%$ M139 & & & & \\
\hline
\end{tabular}

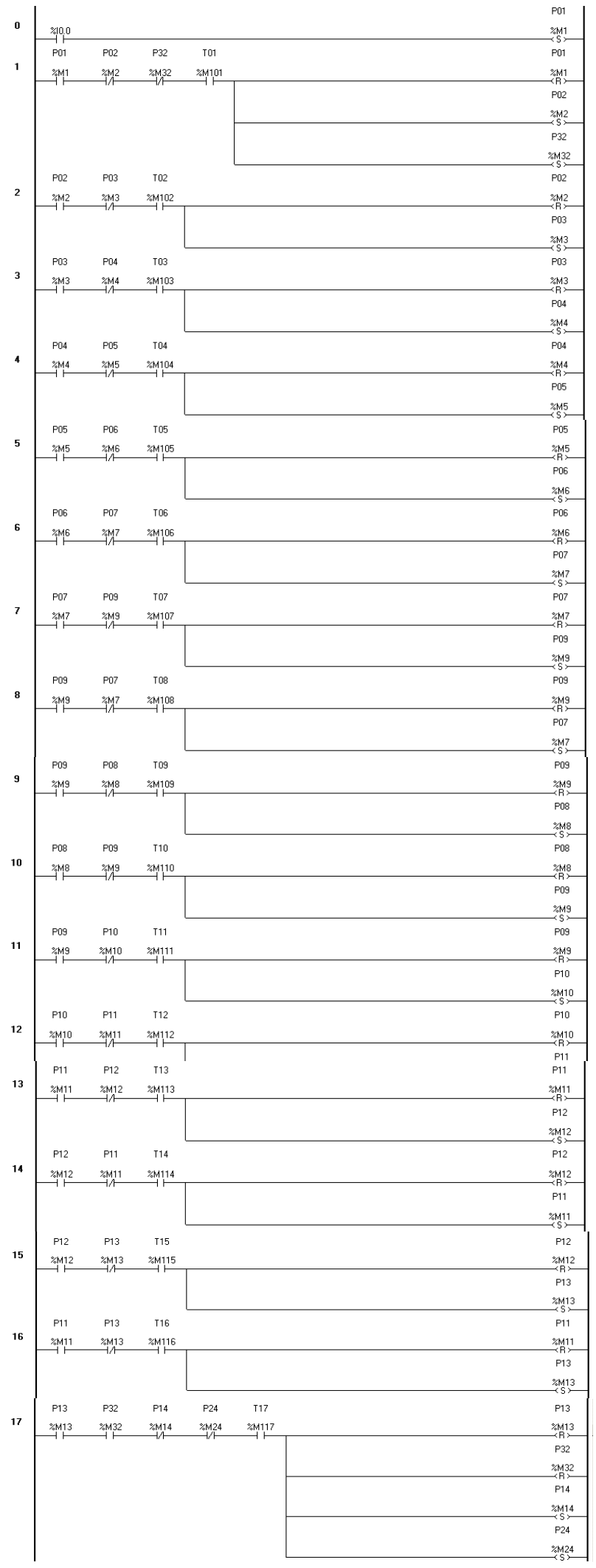




\section{TEKNIK, 41 (2), 2020, 159}

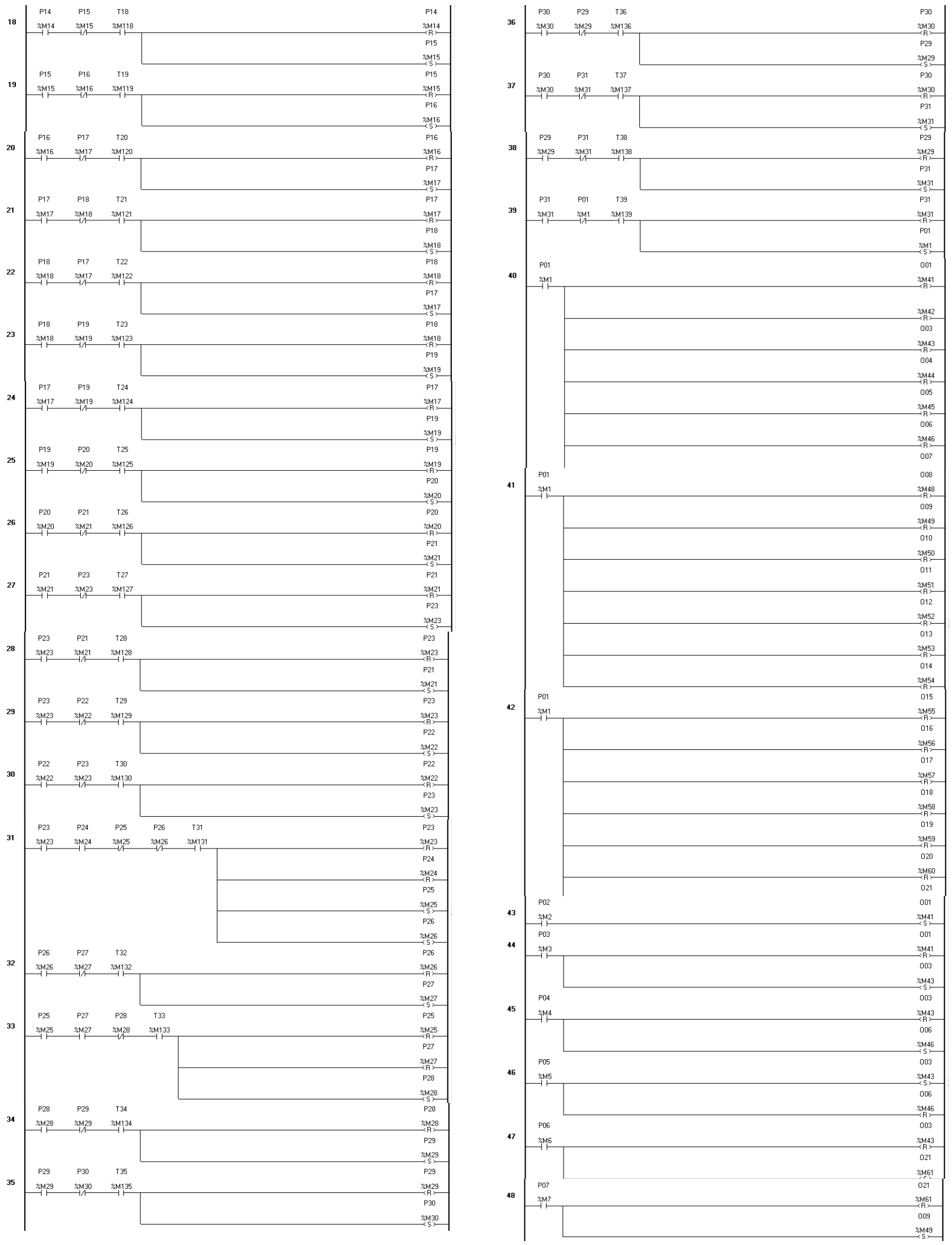


TEKNIK, 41 (2), 2020, 160
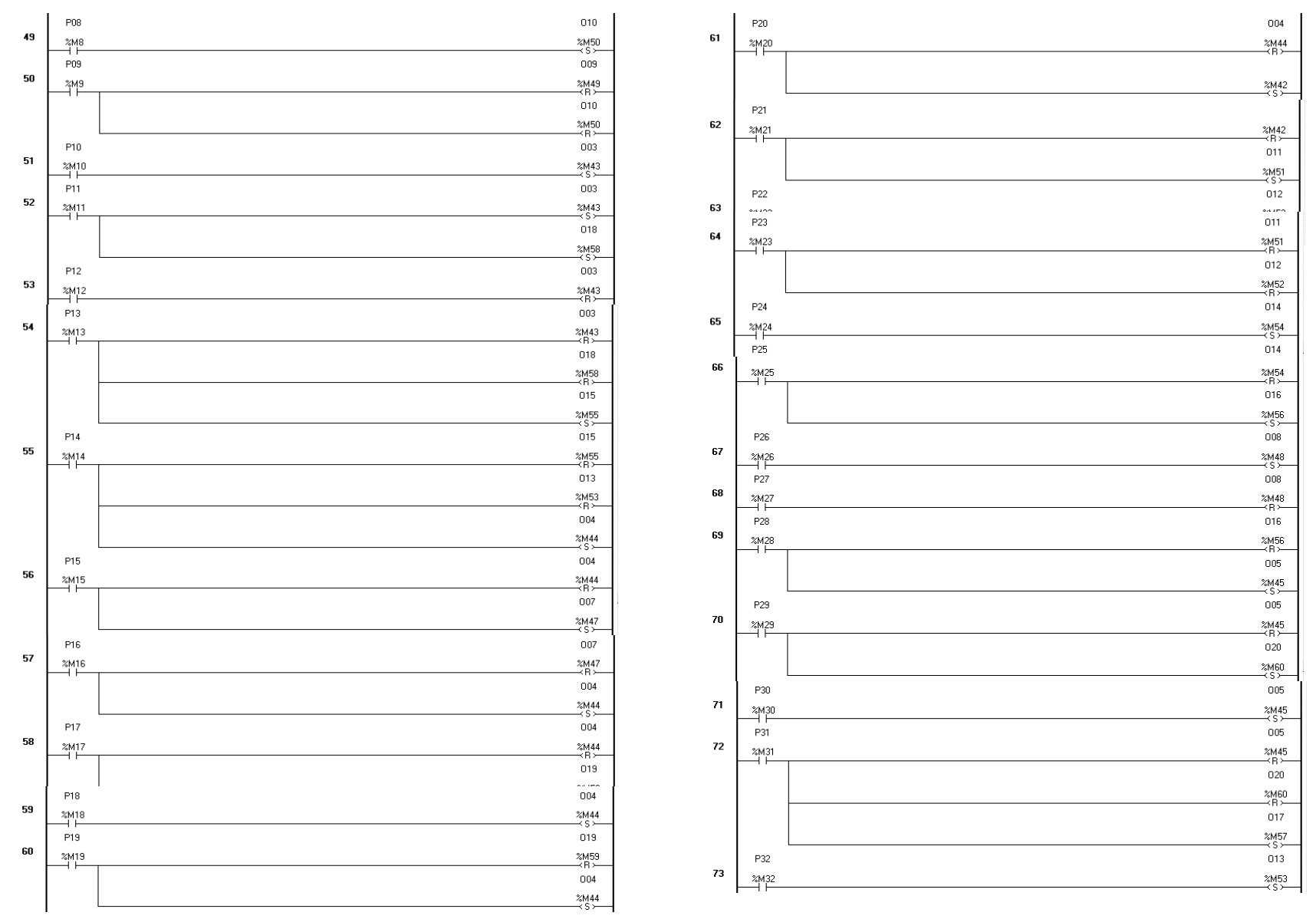

Gambar 4. Program ladder sistem otomasi proses fermentasi bioetanol

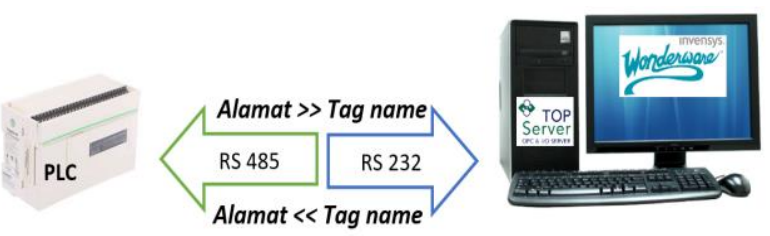

Gambar 5. Koneksi PLC-OPC-HMI pada simulasi

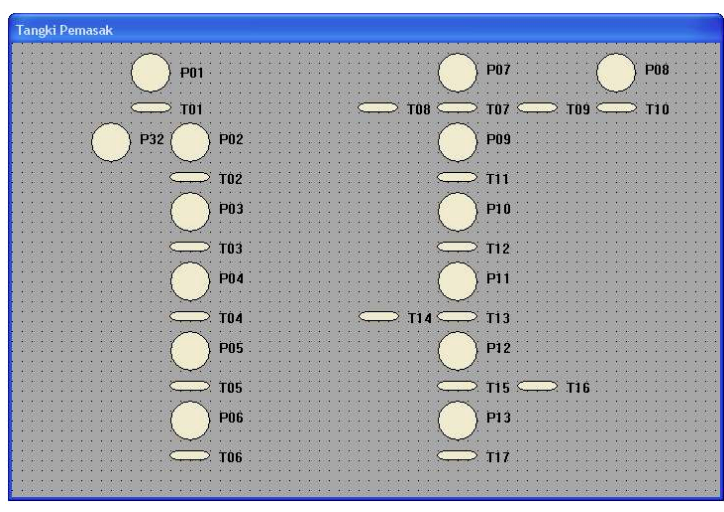

Gambar 6. Tampilan simulasi tangki pemasak

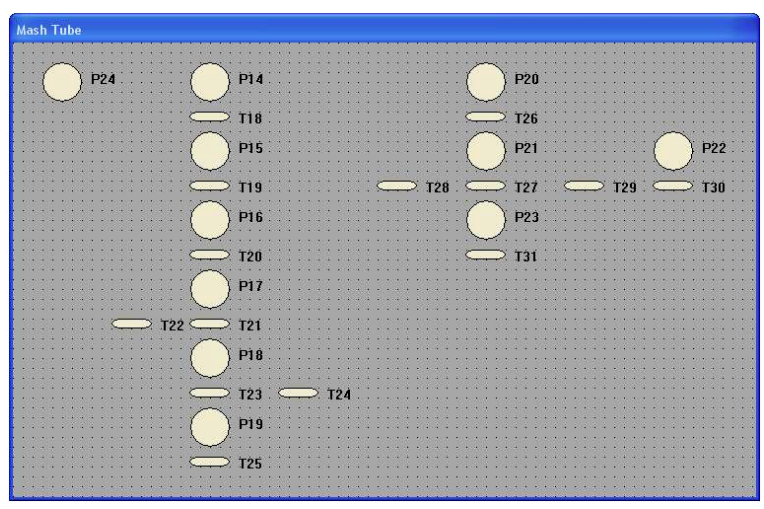

Gambar 7. Tampilan simulasi mash tube 


\section{TEKNIK, 41 (2), 2020, 161}

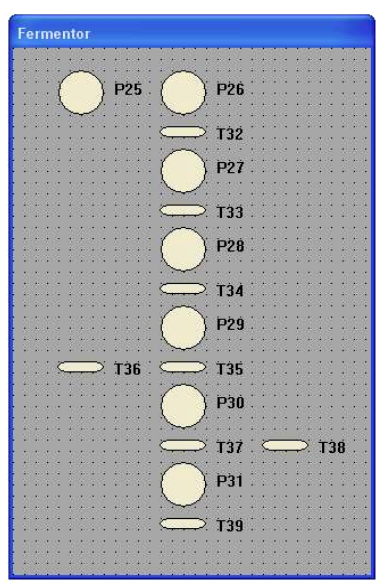

Gambar 8. Tampilan simulasi fermentor

\section{Kesimpulan}

Pada makalah ini telah dibahas teknik pembuatan program ladder untuk sistem otomasi proses fermentasi curah bioetanol dari bahan baku singkong. Sistem otomasi yang dirancang didapatkan dengan menggunakan metode analisis yang dikenal dengan Jala Petri Sinyal Terinterpretasi (JPST). Keunggulan metode analisis dengan JPST dibandingkan dengan metode implementasi langsung yang cenderung coba-coba adalah terdapatnya jaminan kinerja pada sistem otomasi. Oleh karena itu, sistem otomasi berbasis PLC yang dihasilkan akan bekerja secara benar dan terus menerus sesuai dengan urutan proses yang berlaku.

Jaminan kinerja program ladder yang dihasilkan mengikuti hasil analisis invarian yang membuktikan bahwa diagram JPST yang dibangun memenuhi kriteria keterbatasan, keselamatan dan daya hidup. Berdasarkan hasil analisis grafik ketercapaian membuktikan bahwa JPST yang disusun memenuhi kriteria bebas konflik, terminasi dan keluaran benar secara formal dengan memenuhi kriteria yang ditentukan dan memiliki metrik transparansi 0,98 dari maksimal 1. Hal ini berarti bahwa diagram logika ladder yang dihasilkan terdokumentasi dengan baik sehingga dapat diterapkan menjadi program ladder yang siap diaplikasikan dengan menggunakan PLC.

\section{Ucapan Terima Kasih}

Terima kasih disampaikan kepada Kelompok Keahlian Instrumentasi dan Kontrol, Fakultas Teknologi Industri, Intitut Teknologi Bandung atas dana penelitian P3MI 2019 untuk mendanai penelitian ini.

\section{Daftar Pustaka}

Ayten, K. K., \& Kurnaz, O. (2019). Real-time Implementation of Image Based PLC Control for

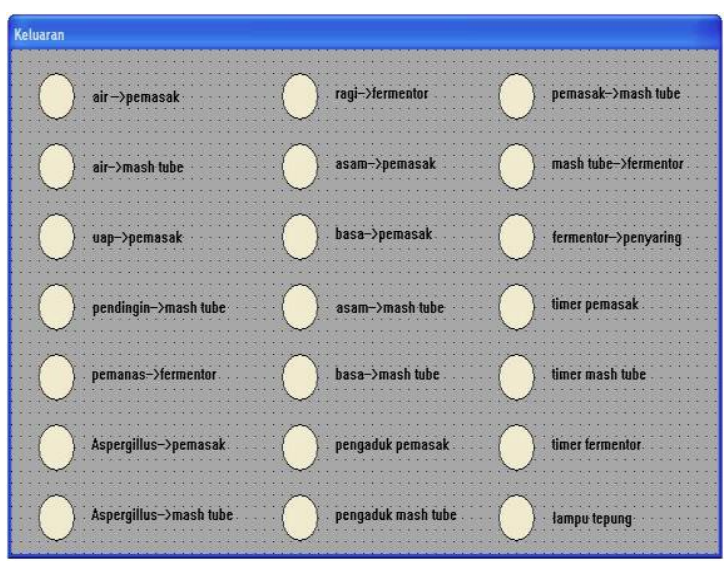

Gambar 9. Tampilan kondisi keluaran

a Robotic Platform. Balkan Journal of Electrical and Computer Engineering, 7(1), 64-71.

Baladhandabany, D., Gowtham, S., Kowsikkumar, T., Gomathi, P., \& Vijayasalini, P. (2015). PLC based automatic liquid filling system. International Journal of Computer Science and Mobile Computing, 4(3), 684-692.

Bargal, N., Deshpande, A., Kulkarni, R., \& Moghe, R. (2016). PLC based object sorting automation. International Research Journal of Engineering Technology (IRJET), 3(07).

Baygin, M., Yetis, H., Karakose, M., \& Akin, E. (2016). An effect analysis of industry 4.0 to higher education. In 2016 15th International Conference on Information Technology Based Higher Education and Training (ITHET) (pp. 1-4). September, IEEE.

Darvas, D., Majzik, I., \& Viñuela, E. B. (2016a). Formal verification of safety PLC based control software. In International Conference on Integrated Formal Methods (pp. 508-522). June, Springer, Cham.

Darvas, D., Viñuela, E. B., \& Majzik, I. (2016b). PLC code generation based on a formal specification language. In 2016 IEEE 14th International Conference on Industrial Informatics (INDIN) (pp. 389-396). July, IEEE.

Frey, G. (2000). Automatic Implementation of Petri Net based Control Algorithms on PLC. In Proc. The 2000 American Control Conference, 4 (pp. 28192823). June, IEEE.

Frey, G., \& Litz, L. (2000). Transparency analysis of Petri net based logic controllers-a measure for software quality in automation. In Proc. the 2000 American Control Conference, 5 (pp. 31823186). June, IEEE.

Frey, G., \& Minas, M. (2001). Internet-based development of logic controllers using Signal 


\section{TEKNIK, 41 (2), 2020, 162}

Interpreted Petri Nets and IEC 61131. In Proc. the 5th World Multi-Conference on Systemics, Cybernetics and Informatics (SCI'01) (pp. 297302). July.

ISA, A. (2002). ISA S88 Batch Standard A General Overview. ISA Philadelphia Section 20 Feb.

Joelianto, E. \& and Loeis, K. (2006). Application in Control of Boiler using Signal Interpreted Petri Nets (SIPN). In Proc. 6th Asian Control Conference (pp. 858-863). July, Bali, Indonesia.

Joelianto, E., \& Dananjaya, A. (2008). Perancangan dan Analisis Sistem Otomasi pada Proses Produksi Bioetanol Menggunakan Jala Petri Sinyal Terintepretasi (JPST). Gematek, 10(1), 45-60.

Julius, R., Schürenberg, M., Schumacher, F., \& Fay, A. (2017). Transformation of GRAFCET to PLC code including hierarchical structures. Control Engineering Practice, 64, 173-194.

Kumar, E. R., Jungral, S., Singh, T., Gupta, A., \& Khan, T. H. (2016a). Effluent Treatment Plant Using PLC. International Journal of Engineering Research and General Sciences, 4(2), 58-65.

Kumar, A., Abdelhadi, A., \& Clancy, C. (2016b). An online delay efficient packet scheduler for M2M traffic in industrial automation. In 2016 Annual IEEE Systems Conference (SysCon) (pp. 1-6). April, IEEE.

Langmann, R., \& Rojas-Peña, L. F. (2016, February). A PLC as an Industry 4.0 component. In 2016 13th International Conference on Remote Engineering and Virtual Instrumentation (REV) (pp. 10-15). IEEE.

Leonardo, A., Joelianto, E., \& Hadisupadmo, S. (2015). Perancangan Safety Shutdown System pada Kepala Sumur Minyak dengan Menggunakan Analisis Pemodelan Petrinet. Jurnal Otomasi, Kontrol dan Instrumentasi, 7(1), 9-17.

Papcun, P., Kajáti, E., \& Koziorek, J. (2018). Human Machine Interface in Concept of Industry 4.0. In 2018 World Symposium on Digital Intelligence for Systems and Machines (DISA) (pp. 289-296). August, IEEE.

Patil, P., Kakade, S., Kantale, S., \& Shinde, D. (2016). Automation in hydroponic system using PLC. International Journal of Scientific and Technical Advancements, 2(2), 69-71.

Petrusich, J., \& Schwarz, H.V. (2017). Industry 4.0 for Process Safety: Handbook, San Bernardino, CA: CreateSpace Independent Publishing Platform.

Shuler, M. L., Kargi, F., \& DeLisa, M. (2017). Bioprocess Engineering: Basic Concepts, vol. 576. Englewood Cliffs, NJ: Prentice Hall.

Vieira, A. D., Santos, E. A. P., de Queiroz, M. H., Leal, A. B., de Paula Neto, A. D., \& Cury, J. E. (2016). A method for PLC implementation of supervisory control of discrete event systems. IEEE Transactions on Control Systems Technology, 25(1), 175-191.

Wang, J. (1998). Timed Petri Nets: Theory and Application. Boston: Kluwer Academic Publishers.

Wanyama, T. (2018) A Practical Approach to Industrial Systems Integration: Industry 4.0 and Industrial Internet of Things, Ed. 2.

Wittenberg, C. (2016). Human-CPS Interactionrequirements and human-machine interaction methods for the Industry 4.0. IFACPapersOnLine, 49(19), 420-425.

Zhou, K., Liu, T., \& Zhou, L. (2015). Industry 4.0: Towards future industrial opportunities and challenges. In 2015 12th International Conference on Fuzzy Systems and Knowledge Discovery (FSKD) (pp. 2147-2152). August, IEEE.

Zhu, H., \& Qiu, X. (2017). The Application of PLC in Sewage Treatment. Journal of Water Resource and Protection, 9(07), 841-850. 